\title{
Dengeli Beslenme Akademik Başarı Testi: Geçerlik ve Güvenirlik Araştırması
}

\section{Selin YILDIZ*， Gonca KEÇECI ${ }^{* *} ， \quad$ Fikriye KIRBAĞ ZENGİN***}

Öz: Fen bilimleri dersi öğretim programında Besinlerimiz/Canlılar ve Yaşam ünitesi içerisinde besin çeşitleri, sağlıklı ve dengeli beslenme, sigara ve alkol kullanımının zararları, sağlıklı beslenmenin faydaları konuları yer almaktadır. Bu çalışma ilkokul 4. sınıf öğrencilerine besinlerimiz ünitesinin içinde yer alan sağlıklı ve dengeli beslenme konusu kazanımları ile uyumlu geçerliği ve güvenilirliği sağlanmış çoktan seçmeli bir başarı testi geliştirmeyi hedeflemiştir. Başarı testi 2017-2018 eğitim öğretim yılında, basit tesadüfî örneklemle belirlenen 127 ilkokul 4. sınıf öğrencisine uygulanmıştır. Başlangıçta 35 soru olarak hazırlanan testin kapsam geçerliği sağlamak amacı ile uzman görüşü alınmıştır. Uzman görüşleri doğrultusunda gerekli düzeltmeler yapılan test 30 soruya düşürülüp madde analizine tabi tutulmuştur. Madde analizi sonrasında 10 sorunun çıkarıldığı ölçek, 20 soru olarak son halini almıştır. Dengeli beslenme başarı testinin cronbach alpha katsayısının .817, spearman brown iki yarı test korelasyon değerinin ise .70 ve pearson korelasyon değerinin .775 olduğu görülmüştür. Yapılan tüm analizler sonucunda ölçeğin öğrencilerin dengeli beslenme konusuna ilişkin bilgilerini ölçmek için kullanılabilecek geçerli ve güvenilir bir ölçme aracı olduğu belirlenmiştir.

Anahtar Kelimeler: Dengeli Beslenme Başarı Testi, Fen Eğitimi, Test Geliştirme.

\section{Balanced Nutrition Academic Achievement Test: Validity and Reliability Research}

Abstract: The nutritional variants, balanced nutrition, benefits of diet and damages of alcohol are included in the Our Food/Living Things and Life Units subjects of the science curriculum.

\footnotetext{
*Yüksek Lisans Öğrencisi, Fırat Üniversitesi, Eğitim Bilimler Enstitüsü, Email: slnylddz@hotmail.com, Orcid No: 00000001-8134-0864.

**Doç.Dr., Fırat Üniversitesi, Eğitim Fakültesi, Matematik ve Fen Bilimleri Bölümü, Email: gkececi@firat.edu.tr,_Orcid No: 0000-0002-2582-3850

***Prof. Dr., Frrat Üniversitesi, Eğitim Fakültesi, Matematik ve Fen Bilimleri Bölümü, Email: fkzengin@gmail.com, Orcid No: 0000-0002-0547-8746.
} 
The aim of this research is to develop a multiple choice achievement test which is valid and reliable in accordance with the balanced nutrition gains of the 4th grade students in the unit called “Our Food/ Living Things and Life”. The achievement test was applied to 127 primary school 4th year students who were determined by simple random sampling in 2017-2018 academic year. Initially, 35 questions were prepared and expert opinion was obtained in order to provide scope validity. In accordance with the expert opinions, the necessary corrections were made and the test was reduced to 30 questions and the item was analyzed. After the item analysis, 10 questions were removed and 20 questions remained. The cronbach alpha coefficient was .817, spearman brown two half test correlation value was .70, and pearson correlation value was .775. As a result of all analyzes, it has been determined that the scale is a valid and reliable measurement tool that can be used to measure students' knowledge on balanced nutrition.

Keywords: Balanced Nutrition Achievement Test, Science Education, Test Development.

\section{Giriş}

Eğitim aslında istenilen nitelikte bireylerin yetiştirilmesini planlamaktır. Bu nedenle ilk olarak bireyde olması gereken nitelikler belirlenmeli, ikinci olarak ise bu niteliklerin nasıl kazandırılacağı planlanmalı, son aşamada ise bu özellikler ölçülüp değerlendirilmelidir (Alkan, 2002). Ölçme genel anlamıyla bir özelliği gözlemlemek ve gözlem sonuçlarını sayı ve sıfatlarla belirtmektir. Değerlendirme ise ölçme sonuçlarını bir ölçüte veya ölçütlere vurarak ölçülen nitelik üzerinde karara varma sürecidir (Turgut ve Baykul, 2010). Eğitim-öğretim sürecinde ölçme ve değerlendirme sürecini ayrı tutmak mümkün değildir.

Ölçme ve değerlendirme; öğrencilerin; derse hazır bulunuşluk seviyelerini tespit etmesi, ünite sonunda öğrencilerin kavramları ne derece gerçekleştirdiğini belirlenmesi, öğrenmenin ne kadar gerçekleştiğini belirlemesi ve öğrencilerin öğrenme eksiklerini giderilebilmesi, açısından ölçme ve değerlendirme mühim bir yere sahiptir. Bireylerin kendilerine aktarılan bilgiyi ne derece aldıklarının belirlenmesi, onların akademik başarılarının ölçülmesi ve değerlendirilmesi ile mümkündür. Akademik başarı; bir zaman dilimi içerisinde öğrencilerin işlenen konulara ile ilgili sahip oldukları bilgi ve becerilerdir. Öğrenci başarısını ölçmek ve değerlendirmek amacı ile birçok ölçme aracı mevcuttur. Açık uçlu, doğru yanlış, boşluk doldurma, eşleştirme ve çoktan seçmeli sorular gibi ölçme araçları öğrenci başarısını ölçmek için kullanılan ölçme araçlarından bazılarıdır (Yaman, 2003). Ölçme araçlarının her birinin birbirine göre üstün ve 
eksik yanları bulunmaktadır. Yapılan araştırmalara göre öğrencilerin başarılarını belirlemek için en çok kullanılan ölçme aracı mülakatlardan sonra çoktan seçmeli testler olduğu bulunmuştur (Kempa, 1986; Ogan Bekiroğlu, 2004). Çoktan seçmeli testler, diğer ölçme araçlarına göre çok sayıda soru sorma olanağı tanıması sayesinde öğretilen konuların tümünü kısa zamanda ölçmeyi sağlayan son zamanlarda sıkça kullanılan ölçme araçlarındandır (Kempa, 1986; Ogan Bekiroğlu, 2004). Hazırlanan başarı testleri standartlaştırma aşamalarından geçmektedir. Yani güvenilir ve geçerlik dereceleri yeterince sağlanmış başarı testleri hazırlanmaktadır (Narlı ve Başer, 2008).

Büyüköztürk (2011)'de söylemiş olduğu gibi ölçme aracında geçerlik, testin öğrencinin ölçülmek istenen niteliğinin ne kadar doğru ölçtüğüyle alakalıdır. Bu nedenle uygulanan ölçme tekniklerinin güvenilir olması gerekmektedir. Ölçme sonuçlarının güvenirliğini; Turgut (1990) “ölçme sonuçlarının tesadüfi hatalardan arınmanın bir ölçüsü” olarak nitelendirmiş, Crocker ve Algina (1986) ise "belirli bir niteliği ölçmek için gerçekleştirilen ölçümlerin aynı bireyler üzerinde benzer koşullarda tekrar edilebilirliği”" olarak tanımlamıştır $\mathrm{Bu}$ nedenle ölçme araçlarının dahilinde bulunan her maddenin özelliklerinin saptanması geçerli ve güvenilir bir ölçüm açısından büyük önem arz etmektedir.

Eğitim araştırmalarında çoktan seçmeli sorulardan oluşan geçerli ve güvenilir başarı testlerinin geliştirilmesine yönelik birçok çalışma mevcuttur (Akdağ ve Tok, 2008; Jayanthi, 2014; Narlı ve Başer, 2008; Samaie ve Khosravian, 2014; Ünal ve Çelikkaya, 2009). Gürbüzöztürk, Aktı Aslan, Et (2017) ilkokul 8. sınıf hücre bölünmesi ve kalıtım konusu kazanımlarına uygun olarak geçerlik ve güvenirliği sağlanmış bir başarı testi geliştirmiştir. Türkmen (2005) canlıların doğa ile iletişimi ünitesi kazanımlarına uygun ilkokul 5.sınıflar için bir başarı testi geliştirmiştir. Akbulut (2010), çalışmasında ilkokul 8. sınıf kaldırma kuvveti ve yüzme konusu kazanımlarına uygun başarı testi geliştirmiştir. Gönen, Kocakaya ve Kocakaya (2011) ortaöğretim fizik programında yer alan dinamik konusuna ilişkin güvenirliği ve geçerliği yüksek bir başarı testi geliştirmeyi amaçlamıştır. Çakır ve Aldemir (2011) üniversite ve başarılı lise sınıflarında kullanılmak üzere iki aşamalı genetik kavram tanı testi geliştirmeyi ve bu testin geçerlik ve güvenirlik araştırması yapmayı amaçlamışlardır. Demir, Kızılay ve Bektaş (2016) ilkokul 7. sınıf çözeltiler konusu kazanımları ile uyumlu bir başarı testi geliştirmiştir.

Hızla gelişmekte ve değişmekte olan dünyada bu gelişmelere paralel olarak görülen en büyük değişimlerden biride beslenme alışkanlıklarında görülmektedir. Bu değişimle birlikte başta obezite olmak üzere birçok hastalık ortaya çıkmıştır. $\mathrm{Bu}$ nedenle dengeli beslenme konusunun öğretimi oldukça önem kazanmıştır. Bu konuda çok geç kalınmadan çalışmalar 
yapılmalıdır. Ancak alanyazın incelendiğinde dengeli beslenme konusuna yönelik akademik çalışmalarda kullanılabilecek geçerli ve güvenilir olan ölçme araçlarının sınırlı olduğu görülmüştür.

Beslenme alışkanlıklarını tespit etmek amaçlı yapılan çalışmaların büyük çoğunluğunun belirli süre için beslenme alışkanlığını tespit eden, gözleme dayalı anket ve formlar kullanılarak yapıldığı ve lisans düzeyinde örneklem gruplarıyla çalışıldığı tespit edilmiştir (Bağc1 ve Akdağ, 1992; Budak, Özer, Kovalı ve İnceiş, 2005; Çelik ve Toksöz, 1999; Iş1ksoluğu, 1986; Kızıltan, 2000; Saygın, Öngel, Çalışkan, Yağlı, Has, Gonca, ve Kurt, 2011; Süel, Şahin, Karakaya ve Savucu, 2006; Şanlıer ve Güler, 2005).

Beslenme alışkanlıklarını ölçmede tutum testlerinin kullanıldığı çalışmalara da rastlanmıştır (Ataman, 2009; Tanrıverdi, Savaş, Gönüllüoğlu, Kurdal ve Balık, 2011; Uskun ve Şabapl1, 2013). Bilgi düzeyi ölçen testler sınırlı düzeydedir (Çongar ve Özdemir, 2004; Mertoğlu, 2002; Obal1, 2009; Ünver, 2004). Dengeli beslenme ile ilgili yapılan bazı araştırmalara aşağıda yer verilmiştir.

Ünver (2004), besin grupları konusunda verilen beslenme eğitiminin 5-6 yaş öğrencilerinin beslenme bilgisi ve davranışlarına olan etkisini belirlemek amacıyla gerçekleştirdiği çalışmasında veri toplama aracı olarak "Besin Grupları Bilgisi Edinme Formu" kullanmış ayrıca velilere bir form göndermiştir. Araştırmada deney grubu öğrencilerinin kontrol grubuna göre besin gruplarına ilişkin bilgi düzeyleri ve yemek yeme davranışlarında olumlu yönde gelişmeler bulunmuştur.

Obalı (2009), altı yaş okul öğrencileriyle gerçekleştirdiği proje yaklaşımıyla beslenme eğitiminin, öğrencilerin beslenme bilgi düzeylerine etkisini araştırmıştır. Veri toplama aracı olarak Ünver (2004) tarafından kullanılan Besin Grupları Bilgisi Saptama Formu kullanılmıştır. Çalışmada proje yaklaşımı kullanılarak verilen eğitimin deney grubundaki öğrencilerin kontrol grubuna oranla bilgi düzeylerine katkı sağladığı bulunmuştur.

Mertoğlu (2002), sekizinci sınıf öğrencilerinin aktif öğrenmenin beslenme kavramını öğrenmelerine etkisini araştırdığg çalışmasında, 156 öğrenci ile çalışmıştır. Deneysel yöntemle yürüttüğü çalışmada, çoktan seçmeli sorulardan oluşan bilgi-başarı testi ve tutum ölçeği kullanarak veri toplamıştır. Öğrencilerinin dengeli beslenme kavramını öğrenmelerinde aktif öğretim yönteminin fen bilgisi dersine yönelik olumlu tutumlarında ve başarılarında etkili olduğu bulunmuştur. 
İrcal Sümbül (2009), dört altı yaş arası öğrencilerin yetersiz ve dengesiz beslenme alışkanlıklarını belirlemek amacıyla 17 deney 17 kontrol grubu olmak üzere 34 öğrenci velisiyle çalışmıştır. Kullanılan anketler velilere uygulanmıştır.

$\mathrm{Bu}$ çalışma alanda hissedilen ihtiyaçtan dolayı ilkokul 4. sınıf öğrencilerine Besinlerimiz/Canlılar ve Yaşam ünitesinin içinde yer alan sağlıklı ve dengeli beslenme konusu kazanımları ile uyumlu geçerliği ve güvenilirliği sağlanmış çoktan seçmeli bir başarı testi geliştirmeyi hedeflemiştir. Hazırlanan test sayesinde öğretmen ve araştırmacıların, öğrencilerin hazır bulunuşluklarını ve öğrenme düzeylerini belirleyebileceklerine inanılmaktadır.

\section{Yöntem}

$\mathrm{Bu}$ çalışma ile ilkokul 4. sınıf öğrencilerinin Besinlerimiz/Canlılar ve Yaşam ünitesi içerisinde yer alan dengeli beslenme konusuna dair başarılarını ölçmek amacı ile çoktan seçmeli başarı testi geliştirilip geçerlik ve güvenirlik analizlerine tabi tutulmuştur. Bu kazanımlara uygun sorular çeşitli kaynaklardan toplanmış ve incelenmiştir. Belirlenen kazanımlara uygun 35 soru yazılmıştır. Başarı testi son halini almadan önce uzman görüşüne sunulmuş, uzman görüşleri doğrultusunda gerekli düzenlemeler yapılmıştır. Başarı testine son hali verildikten sonra 127 ilkokul 4. sınıf öğrencisine uygulanmış ve madde analizine tabi tutulup, geçerlik güvenirlik katsayıları hesaplanmıştır.

\section{Örneklem}

$\mathrm{Bu}$ çalışmada örneklem basit seçkisiz örnekleme yoluyla seçilmiştir. Bu çalışmanın örneklemini 2017-2018 eğitim-öğretim yılında Elazığ il merkezinde öğrenim gören 127 ilkokul 4. sınıf öğrencisi oluşturmaktadır.

\section{Test Geliştirme Süreci}

Dengeli Beslenme Başarı Testi geliştirme sürecinde ilk olarak 4. sınıf Fen Bilimleri dersinin öğretim programından Besinlerimiz/Canlılar ve Yaşam ünitesi dâhilindeki konu başlıkları, kavramlar ve kazanımlar belirlenmiştir. İlköğretim 4. sınıf Besinlerimiz/Canlılar ve Yaşam ünitesi; Besin içerikleri, su, mineral, gıda saklama koşulları, dengeli beslenme, obezite, besin israfı, sigara ve alkol konularını içeren 6 kazanımdan oluşmaktadır. Çalışma kapsamında sağlıklı ve dengeli beslenme konusu kazanımları kapsayacak şekilde 35 tane çoktan seçmeli 
sorudan oluşan soru havuzu hazırlanmıştır. Hazırlanan 35 soru; madde kökü, soruda bulunan çeldiriciler, soruların kazanımları kapsama durumu açısından beş öğretim üyesinin (üç Profesör, iki Dr. Öğr. Üyesi) görüşüne arz edilmiştir. Uzman görüşleri ile doğrultusunda soruların bazıları düzeltilerek, bazıları ise testten çıkartılarak soru sayısı 30'a düşürülmüştür. 30 maddelik test ilkokul öğrencilerine uygulanarak madde analizine tabi tutulmuştur.

\section{Verilerin Analizi}

Uzman görüşleri ile paralel olarak düzenlenen testin yapı geçerliliğini sağlamak amaciyla madde analizine tabi tutulmuştur (Turgut, 1992). Pilot uygulamaya 69'u kız, 58'i erkek olmak üzere toplam 127 ilkokul 4.sınıf öğrencisi katılmıştır. Test öğrencilerin doğru cevapladığı her maddeye "1" yanlış ve boş cevaplara “0” puan verilerek puanlanmıştır. Öğrencilerin başarı testinden aldıkları puanlar başarı sırasına göre sıralanmıştır. Sıralama yapılan puanların en yükssekten en düşüğe doğru grubun \%27 si belirlenmiştir. Aynı işlem en düşük puandan en yüksek puana doğru da yapılmıştır. Böylece alt ve üst gruplar belirlenmiştir. Daha sonra üst ve alt gruplarda yer öğrencilerin doğru şıkka ve diğer şıklara verdikleri cevaplar, ayrıca kaç kişinin ilgili maddeyi boş bıraktığı belirlenmiştir ve madde analizine tabi tutulmuştur. Elde edilen veriler doğrultusunda madde ayırt edicilik indeksi 0.40 ve daha büyük ise madde çok iyi 0.30-0.39 arasında ise madde oldukça iyi, 0.20-0.29 arasında ise madde zorunlu hallerde kullanılabilir olarak nitelendirilmiştir, 0.19 ve daha küçük ise madde testten çıkarılmıştır (Turgut, 1992; Tekin, 2000).

\section{Bulgular}

Test maddelerinin yapı geçerliliğinin sağlanmak amacı ile madde analizi tabi tutulmuş ve madde analizi sonucunda hesaplanan madde ayırt edicilik indeksleri ve güçlük dereceleri Tablo 1'de verilmiştir. 
YYÜ Ĕ̌itim Fakültesi Dergisi (YYU Journal of Education Faculty), 2019; 16(1):848-868, http://efdergi.yyu.edu.tr

Tablo 1.

Geliştirilen Başarı Testindeki Maddelerin Ayırt Edicilik İndeksleri (d) ve Güçlük Dereceleri (p)

\begin{tabular}{|c|c|c|c|c|c|c|c|c|c|c|}
\hline $\begin{array}{l}\text { Soru } \\
\text { No }\end{array}$ & Gruplar & $A$ & B & $C$ & D & Boş & Dolu & $\begin{array}{l}\text { Toplam } \\
\text { Puan }\end{array}$ & $d$ & $p$ \\
\hline \multirow[t]{2}{*}{1} & Üst Grup & 2 & - & 3 & 29 & 0 & 34 & 29 & 0.47 & 0.61 \\
\hline & Alt Grup & 6 & 5 & 8 & 13 & 0 & 34 & 13 & & \\
\hline \multirow[t]{2}{*}{2} & Üst Grup & - & - & 34 & - & 0 & 34 & 34 & 0.44 & 0.91 \\
\hline & Alt Grup & 5 & 7 & 16 & 6 & 0 & 34 & 16 & & \\
\hline \multirow[t]{2}{*}{3} & Üst Grup & 4 & 28 & 1 & $\overline{1}$ & 0 & 34 & 28 & 0.41 & 0.61 \\
\hline & Alt Grup & 7 & 14 & 6 & 7 & 0 & 34 & 14 & & \\
\hline \multirow[t]{2}{*}{4} & Üst Grup & 2 & - & - & 32 & 0 & 34 & 32 & 0.32 & 0.77 \\
\hline & Alt Grup & 6 & 3 & 4 & 21 & 0 & 34 & 21 & & \\
\hline \multirow[t]{2}{*}{5} & Üst Grup & 1 & 19 & 3 & 9 & 0 & 34 & 19 & 0.35 & 0.38 \\
\hline & Alt Grup & 7 & 7 & 5 & 12 & 0 & 34 & 7 & & \\
\hline \multirow[t]{2}{*}{6} & Üst Grup & 29 & - & - & 5 & 0 & 34 & 29 & 0.50 & 0.60 \\
\hline & Alt Grup & 12 & 8 & 6 & 9 & 0 & 34 & 12 & & \\
\hline \multirow[t]{2}{*}{7} & Üst Grup & 32 & - & - & 2 & 0 & 34 & 32 & 0.14 & 0.86 \\
\hline & Alt Grup & 27 & 2 & 2 & 3 & 0 & 34 & 27 & & \\
\hline \multirow[t]{2}{*}{8} & Üst Grup & - & 4 & 28 & - & 0 & 34 & 28 & 0.44 & 0.6 \\
\hline & Alt Grup & 4 & 10 & 13 & 5 & 0 & 34 & 13 & & \\
\hline \multirow[t]{2}{*}{9} & Üst Grup & - & - & 34 & - & 0 & 34 & 34 & 0.26 & 0.92 \\
\hline & Alt Grup & 3 & 2 & 25 & 4 & 0 & 34 & 25 & & \\
\hline \multirow[t]{2}{*}{10} & Üst Grup & - & - & - & 34 & 0 & 34 & 34 & 0.32 & 0.83 \\
\hline & Alt Grup & 4 & 3 & 4 & 23 & 0 & 34 & 23 & & \\
\hline \multirow[t]{2}{*}{11} & Üst Grup & - & - & 2 & 31 & 0 & 34 & 31 & 0.23 & 0.79 \\
\hline & Alt Grup & 3 & 3 & 5 & 23 & 0 & 34 & 23 & & \\
\hline \multirow[t]{2}{*}{12} & Üst Grup & - & 34 & - & - & 0 & 34 & 34 & 0.32 & 0.83 \\
\hline & Alt Grup & 4 & 23 & 7 & - & 0 & 34 & 23 & & \\
\hline \multirow[t]{2}{*}{13} & Üst Grup & 34 & - & - & - & 0 & 34 & 34 & 0.29 & 0.79 \\
\hline & Alt Grup & 22 & 2 & 7 & 3 & 0 & 34 & 22 & & \\
\hline \multirow[t]{2}{*}{14} & Üst Grup & - & 32 & 2 & - & 0 & 34 & 32 & 0.35 & 0.79 \\
\hline & Alt Grup & 4 & 21 & 5 & 4 & 0 & 34 & 21 & & \\
\hline
\end{tabular}


YYÜ Ĕ̌itim Fakültesi Dergisi (YYU Journal of Education Faculty), 2019; 16(1):848-868, http://efdergi.yyu.edu.tr

\begin{tabular}{|c|c|c|c|c|c|c|c|c|c|c|}
\hline \multirow[t]{2}{*}{15} & Üst Grup & 1 & - & - & 33 & 0 & 34 & 33 & \multirow[t]{2}{*}{0.23} & \multirow[t]{2}{*}{0.88} \\
\hline & Alt Grup & 3 & 2 & 3 & 26 & 0 & 34 & 26 & & \\
\hline \multirow[t]{2}{*}{16} & Üst Grup & - & - & - & 34 & 0 & 34 & 34 & \multirow[t]{2}{*}{0.35} & \multirow[t]{2}{*}{0.82} \\
\hline & Alt Grup & 3 & 6 & 3 & 22 & 0 & 34 & 22 & & \\
\hline \multirow[t]{2}{*}{17} & Üst Grup & 5 & 20 & 6 & 3 & 0 & 34 & 20 & \multirow[t]{2}{*}{0.17} & \multirow[t]{2}{*}{0.5} \\
\hline & Alt Grup & 6 & 14 & 9 & 5 & 0 & 34 & 14 & & \\
\hline \multirow[t]{2}{*}{18} & Üst Grup & - & 34 & - & - & 0 & 34 & 34 & \multirow[t]{2}{*}{0.29} & \multirow[t]{2}{*}{0.85} \\
\hline & Alt Grup & 2 & 24 & 5 & 3 & 0 & 34 & 24 & & \\
\hline \multirow[t]{2}{*}{19} & Üst Grup & - & - & - & 34 & 0 & 34 & 34 & \multirow[t]{2}{*}{0.35} & \multirow[t]{2}{*}{0.82} \\
\hline & Alt Grup & 4 & 3 & 6 & 21 & 0 & 34 & 21 & & \\
\hline \multirow[t]{2}{*}{020} & Üst Grup & - & 33 & 1 & - & 0 & 34 & 33 & \multirow[t]{2}{*}{0.44} & \multirow[t]{2}{*}{0.75} \\
\hline & Alt Grup & 7 & 18 & 5 & 4 & 0 & 34 & 18 & & \\
\hline \multirow[t]{2}{*}{21} & Üst Grup & - & - & 34 & - & 0 & 34 & 34 & \multirow[t]{2}{*}{0.32} & \multirow[t]{2}{*}{0.83} \\
\hline & Alt Grup & 3 & 2 & 23 & 6 & 0 & 34 & 23 & & \\
\hline \multirow[t]{2}{*}{22} & Üst Grup & & 34 & & & 0 & 34 & 34 & \multirow[t]{2}{*}{0.58} & \multirow[t]{2}{*}{0.70} \\
\hline & Alt Grup & 8 & 14 & 7 & 5 & 0 & 34 & 14 & & \\
\hline \multirow[t]{2}{*}{23} & Üst Grup & - & - & - & 34 & 0 & 34 & 34 & \multirow[t]{2}{*}{0.35} & \multirow[t]{2}{*}{0.82} \\
\hline & Alt Grup & 3 & 4 & 5 & 22 & 0 & 34 & 22 & & \\
\hline \multirow[t]{2}{*}{24} & Üst Grup & 32 & - & 1 & 1 & 0 & 34 & 32 & 0.52 & 0.73 \\
\hline & Alt Grup & 16 & 7 & 6 & 5 & 0 & 34 & 16 & & \\
\hline 25 & Üst Grup & 1 & - & 33 & - & 0 & 34 & 33 & 0.41 & 0.76 \\
\hline & Alt Grup & 5 & 6 & 19 & 4 & 0 & 34 & 19 & & \\
\hline 26 & Üst Grup & 7 & 15 & 6 & 6 & 0 & 34 & 15 & 0.23 & 0.32 \\
\hline & Alt Grup & 7 & 7 & 8 & 10 & 0 & 34 & 7 & & \\
\hline 27 & Üst Grup & 1 & 31 & 2 & - & 0 & 34 & 31 & 0.44 & 0.67 \\
\hline & Alt Grup & 8 & 15 & 7 & 4 & 0 & 34 & 15 & & \\
\hline 28 & Üst Grup & 1 & 1 & 31 & - & 0 & 34 & 31 & 0.44 & 0.67 \\
\hline & Alt Grup & 6 & 8 & 15 & 5 & 0 & 34 & 15 & & \\
\hline 29 & Üst Grup & 1 & - & - & 33 & 0 & 34 & 33 & 0.64 & 0.64 \\
\hline & Alt Grup & 9 & 8 & 6 & 11 & 0 & 34 & 11 & & \\
\hline 30 & Üst Grup & - & - & 34 & - & 0 & 34 & 34 & 0.54 & 0.73 \\
\hline & Alt Grup & 5 & 7 & 16 & 6 & 0 & 34 & 16 & & \\
\hline
\end{tabular}

Tablo 2. 
Pilot madde ayırt edicilik indeksi değerlerine göre soruların dağılımı

\begin{tabular}{ll}
\hline D DEĞERİ & TOPLAM \\
\hline 0.40 ve daha büyük & 13 \\
\hline $0.39-0.30$ & 9 \\
\hline $0.29-0.20$ & 6 \\
\hline 0.19 & 2 \\
\hline
\end{tabular}

Tablo 1 ve Tablo 2 incelendiğinde ayırt edicilik indeksi 0.40 ve büyük olan 1, 2, 3, 6, 8, 20, 22, 24, 25, 27, 28, 29, 30 numaralı 14 maddenin çok iyi, ayırt edicilik indeksi 0.30- 0.39 arasında olan 4, 5, 10, 12, 14, 16, 19, 21, 23 numaralı dokuz maddenin oldukça iyi madde özelliği gösterdiği görülmektedir (Tekin, 2000). Ayırt edicilik indeksi 0.20 ile 0.29 olan 9, 11, $13,15,18,26$ numaralı altı maddenin ve ayırt edicilik indeksi 0.19 ve daha küçük olan 7, 17 numaralı iki maddenin testten çıkarılması uygun görülmüştür.

Madde güçlük derecesi 0.4 'den küçük olan 5 ve 26 numaralı iki madde zor olması sebebiyle, madde güçlük derecesi 0.8 'den büyük olan 2 numaralı madde ise çok kolay olması sebebiyle testten çıkarılmıştır.

Madde analizi sonrası akademik başarı testi, ayırt edicilik indeksi 0.40 ve üzeri olan 12 madde, maddenin ayırt edicilik indeksinin 0.30- 0.39 arasında 8 madde olmak üzere 20 maddeden oluşacak şekilde düzenlenmiştir.

Test güvenirliğinin incelenmesi adına Cronbach Alpha ve Spearman Brown değerleri İki Yarı Test Güvenirliği ile Toplam Korelasyon Değerleri hesaplanmıştır. Bu değerlere Tablo 3’de yer verilmiştir.

Tablo 3.

Alpha ve Spearman Brown İki Yarı Test Güvenirliği ile Toplam Korelasyon Değerleri

\begin{tabular}{llll}
\hline & Alpha & $\begin{array}{l}\text { Pearson } \\
\text { korelasyonu }\end{array}$ & $\begin{array}{l}\text { Íki yarı test } \\
\text { korelasyonu }\end{array}$ \\
\hline Toplam & .817 & .775 & .70 \\
\hline
\end{tabular}


Tablo 3 incelendiğinde Dengeli beslenme başarı testinin cronbach alpha katsayısının .817 olduğu sonucuna varılmıştır. Cronbach Alpha katsayısının $0.60 \leq \alpha<0.90$ aralığında yer alması, öğrencilerin testten aldıkları puanların oldukça güvenilir olduğunu yansıtmaktadır (Can, 2014). Spearman Brown iki yarı test korelasyon değerinin ise .70 ve Pearson korelasyon değerinin .775 olduğu görülmüştür.

Madde analizi sonrası son hali verilen başarı testine ait kazanım belirtke tablosu aşağıda verilmiştir.

Tablo 4.

Dengeli Beslenme Başarı Testi Kazanım ve Belirtke Tablosu

\begin{tabular}{lll}
\hline Kazanımlar & Maddeler & Madde Sayısı \\
\hline $\begin{array}{l}\text { Canlı yaşamı ve besin içerikleri arasındaki } \\
\text { ilişkiyi açıklar. }\end{array}$ & $3,4,6,8,13,17,19$ & 7 \\
\hline $\begin{array}{l}\text { Su ve minerallerin bütün besinlerde } \\
\text { bulunduğu çıarımını yapar. }\end{array}$ & 10,14 & 2 \\
\hline $\begin{array}{l}\text { Sağlıklı bir yaşam için besinlerin tazeliğinin } \\
\text { ve doğallığının önemini, araştırma verilerine } \\
\text { dayalı olarak tartışır. }\end{array}$ & $2,7,11,16$ & 4 \\
\hline $\begin{array}{l}\text { İnsan sağlığı ile dengeli beslenmeyi } \\
\text { ilişkilendirir. }\end{array}$ & $1,5,9,12,15,18,20$ & 7 \\
\hline
\end{tabular}

Tablo 4 incelendiğinde altı kazanımdan oluşan Besinlerimiz/Canlılar ve Yaşam Ünitesi kazanımlarından dengeli beslenme konusuna yönelik olan dört kazanım hedef alınarak geliştirilmiştir. Dengeli beslenme başarı testinde yer alan maddelerden; 3, 4, 6, 8, 13, 17, 19 numaralı 7 maddenin "Canlı yaşamı ve besin içerikleri arasındaki ilişkiyi açıklar.” kazanımına, 10, 14 numaralı 2 maddenin "Su ve minerallerin bütün besinlerde bulunduğu çıkarımını yapar." kazanımına, 2, 7, 11, 16 numaralı 4 maddenin "Sağlıklı bir yaşam için besinlerin tazeliğinin ve doğallığının önemini, araştırma verilerine dayalı olarak tartışır.” kazanımına, 1, 5, 9, 12, 15, 18, 20 numaralı 7 maddenin ise "İnsan sağlığı ile dengeli beslenmeyi ilişkilendirir." kazanımına yönelik olduğu görülmektedir.

\section{Tartışma ve Sonuç}

$\mathrm{Bu}$ çalışma ilkokul 4. sınıf öğrencilerine Besinlerimiz/Canlılar ve Yaşam ünitesinin içinde yer alan sağlıklı ve dengeli beslenme konusu kazanımları ile uyumlu geçerliği ve 
güvenilirliği sağlanmış çoktan seçmeli bir başarı testi geliştirmeyi hedeflemiştir. Test geliştirme aşamalarına uyularak hazırlanan başarı testi analiz edilmiştir.

Testin kapsam geçerliğini sağlamak amaciyla öğretim üyelerinin görüşüne başvurulması alanyazında yaygın olarak rastlanmaktadır (Akbulut ve Çepni, 2013; Şen ve Eryılmaz, 2011; Bingöl ve Halisdemir, 2017; Gürbüzöztürk, Aslan ve Et, 2017). Uzman görüşleri doğrultusunda çoktan seçmeli başarı testinin istenilen özellikleri ölçüp ölçmediğine ve testin eksik noktalarına odaklanılmıştır. Çoktan seçmeli testin yapı geçerliği sağlamak amacı ile madde analizine tabi tutulmuştur. Madde analizi sonrası akademik başarı testi, ayırt edicilik indeksi 0.40 ve üzeri olan 12 madde, maddenin ayırt edicilik indeksinin 0.30- 0.39 arasında 8 madde olmak üzere 20 maddeden oluşmuştur. Bu değerlere göre testin ayırt ediciliğinin oldukça iyi olduğu sonucuna ulaşılabilir (Tekin, 2000). Dengeli beslenme başarı testinden alınabilecek en az 0 puan; en çok puan ise 20'dir. Çoktan seçmeli akademik başarı testi 4 seçenekli olup, doğru cevaplara " 1 ” yanlış ve boş cevaplara " 0 " puan verilerek toplam 20 puan üzerinden değerlendirme yapılmalıdır.

Dengeli beslenme başarı testi maddelerin madde güçlük indeksi değerleri (p), 0.50 ile 0.83 arasındadır. Bu durumda teste bulunan en zor madde. katılımcıların yarısı tarafından doğru cevaplandırılmıştır. Bu durumda dengeli beslenme başarı testi, anlaşılabilir, öğrenci düzeyine uygun ve kolay olarak tanımlanabilir. Hazırlanan başarı testi için yapılan analizler sonucunda, geçerli ve güvenilir bir test olduğu ortaya konulmuştur.

Dengeli beslenme bireylerin sağlı̆̆ını doğrudan etkilediği için kazanımların erken yaşlardan itibaren kazandırılması önemlidir. Bu açıdan geliştirilen dengeli beslenme başarı testi hem öğrencilere çoktan seçmeli sınav sistemine yönelik sorular çözebilmesi hem de ünite kazanımları başarılarının tespit edilmesinde araştırmacı ve öğretmenlere katkı sağlayacaktır.

Ülkemizde ve birçok ülkede öğrenciler lise ve üniversite giriş sınavlarına girerken çoktan seçmeli testler kullanılmaktadır. Bu çoktan seçmeli testlerin öğretim programlarında yer alan kazanımlarla ne derece uyumlu olduğu tartışma konusudur (Akbulut ve Çepni, 2013). Literatür incelendiğinde, ülkelerde yapılan sınavlarla öğretim programlarındaki paralelliğin incelendiği görülmüştür (Fulmer, 2010; Liu \& Fulmer, 2008; Saderholm \& Tretter, 2008; Sireci ve diğ., 2009; Yan \& Erduran, 2009). Uygulanan sınavlar ile kazanımların paralel olmasının birçok yönden faydası bulunmaktadır. Kazanımlara uygun öğretim gerçekleştirildiği takdirde öğrenciler sınavlarda derslerde öğrenmedikleri konular ile karşılaşmayacaktır. Dolayısıyla daha 
başarılı olacaklardır. Bu gibi sebeplerden ötürü testlerin kazanımlara uygun olarak hazırlanması faydalı olacaktır.

\section{Öneriler}

- Dengeli Beslenme Başarı testi ilkokul 4. sınıf öğrencileri için hazırlanmıştır. Dengeli beslenme konusunun obeziteyle mücadelede önemi düşünüldüğünde, farklı eğitim kademeleri içinde geliştirilmesi önerilmektedir.

- Dengeli Beslenme Başarı testi ilkokul 4. sınıf öğretim programında yer alan Besinlerimiz/Canlılar ve Yaşam ünitesi içerisinde yer alan sağlıklı ve dengeli beslenme konusu kazanımları ile uyumlu hazırlanmıştır. Tüm üniteyi kapsayan bir test geliştirilebilir.

\section{Makalenin Bilimdeki Konumu}

Matematik ve Fen Bilimleri Eğitimi/Fen Bilgisi Eğitimi

\section{Makalenin Bilimdeki Özgünlüğü}

Yapılan literatür taramasında akademik çalışmalarda kullanılan geçerli ve güvenilir olan ölçme araçlarının sınırlı olduğu görülmüştür. Bu nedenle bu çalışmada ilkokul4. sınıf öğrencilerine Besinlerimiz/Canlılar ve Yaşam ünitesinin içinde yer alan sağlıklı ve dengeli beslenme konusu kazanımları ile uyumlu geçerliği ve güvenilirliği sağlanmış çoktan seçmeli bir başarı testi geliştirilmiştir. Hazırlanan test sayesinde öğretmen ve araştırmacıların, öğrencilerin hazır bulunuşluklarını ve öğrenme düzeylerini belirleyebileceklerine inanılmaktadır.

\section{Kaynaklar}

Akbulut, H. İ. ve Çepni, S. (2013). Bir üniteye yönelik başarı testi nasıl geliştirilir? İlköğretim 7. sınıf kuvvet ve hareket ünitesine yönelik bir çalışma. Amasya Üniversitesi Ĕgitim Fakültesi Dergisi, 2(1), 18-44.

Akbulut, H.H. (2010). Sivıların kaldırma kuvveti ve yüzme kavramlarına yönelik probleme dayalı ögrenme uygulaması ve değerlendirilmesi, Yayınlanmamış Yüksek Lisans Tezi, Fen Bilimleri Enstitüsü, Karadeniz Teknik Üniversitesi, Trabzon.

Akdağ, M. ve Tok, H. (2008). Geleneksel öğretim ile powerpoint sunum destekli öğretimin öğrenci erişisine etkisi. Ĕ̆itim ve Bilim, 33(147), 26-34. 
Alkan H. (Eylül, 2002). Matematik öğretiminde belirlenen hedef davranışlar ile kullanılan ölçme araçlarının ilişkisi. V. Ulusal Fen Bilimleri ve Matematik Eğitimi Kongresi. 1618 Eylül, İzmir.

Ataman, Ü. (2009). Okul öncesi beslenme eğitiminde çocuktan çocuğa ĕgitim. Doktora tezi, Sosyal Bilimleri Enstitüsü, Selçuk Üniversitesi, Konya.

Bağcı, T. ve Akdağ, F. (1992). Kentsel ve Yarı Kentsel Alanda İlkokul Beşinci Sınıf Oğrencilerinin Buyume Gelişme Durumlarının ve Beslenme Alışkanlıklarının Değerlendirilmesi. Beslenme ve Diyet Dergisi, 21(1), 25-30.

Bingöl, A. ve Halisdemir, N. (2017). Üniversite öğrencilerinin temel bilgi teknolojileri dersine yönelik akademik başarı testi geliştirme çalışması. The Journal of Academic Social Science Studies, 54, 541-554.

Budak, N., Özer, E., Kovalı, S. ve İnceiş, N. (2005). Kahvaltının öğrencilerin beslenmesine katkısı ve akademik başarıya etkisi. Beslenme ve Diyet Dergisi, 33(1), 47-54.

Büyüköztürk, Ş. (2011). Sosyal bilimler için veri analizi el kitabı: İstatistik, araştırma deseni SPSS uygulamalarl ve yorum. Pegem A Yayıncılık.

Can, A. (2014). SPSS ile bilimsel araştırma sürecinde nicel veri analizi (2. Baskı). Ankara: Pegem A Yayıncilik.

Crocker, L., \& Algina, J. (1986). Introduction to classical and modern test theory. Holt, Rinehart and Winston, 6277 Sea Harbor Drive, Orlando.

Çakır, M. ve Aldemir, B. (2011). İki aşamalı genetik kavramlar tanı testi geliştirme ve geçerlik çalışması. Mustafa Kemal Üniversitesi Sosyal Bilimler Enstitüsü Dergisi, 8(16), 335353.

Çelik, F. ve Toksöz, P. (1999). Dicle Üniversitesi beden eğitimi ve spor bölümünde okuyan öğrencilerin besin tüketim düzeyleri ve beslenme alışkanlıkları. Beslenme ve Diyet Dergisi, 28(1), 4-9.

Çongar, O. ve Özdemir, L. (2004). Sivas il merkezinde beden eğitimi öğretmenlerinin genel beslenme ve sporcu beslenmesi ile ilgili bilgi düzeyleri. CÜ Tıp Fakültesi Dergisi, 26(3), 113-118.

Demir, N., Kızılay, E. ve Bektaş O. (2016). 7. sınıf çözeltiler konusunda başarı testi geliştirme: geçerlik ve güvenirlik çalışması. Necatibey Eğitim Fakültesi Elektronik Fen ve Matematik Ë̆itimi Dergisi (EFMED), 10(1), 209-237.

Fulmer, G.W. (2010). Estimating critical values for strength of alignment among curriculum assessments, and instruction. San Francisco, US. 
Gönen, S., Kocakaya, S. ve Kocakaya, F. (2011). Dinamik konusunda geçerliği ve güvenirliği sağlanmış bir başarı testi geliştirme çalışması. Yüzüncü Yıl Eğitim Fakültesi Dergisi, 8(1), 40-57.

Gürbüzöztürk, O., Aktı Aslan, S. ve Et, S. (2017). 8. sınıf fen ve teknoloji programı "Hücre Bölünmesi ve Kalıtım” ünitesinin kazanımlarına ulaşma düzeyinin değerlendirilmesi. İnönü Üniversitesi Ĕ̆itim Fakültesi Dergisi, 18(2), 62-72.

Işıksoluğu, M.K. (1986). Yükseköğrenim yapan kız öğrencilerin beslenme durumu ve buna beslenme eğitiminin etkisi. Beslenme ve Diyet Dergisi, 15, 55-70.

Jayanthi, J. (2014). Development and validation of an achievement test in mathematics. International Journal of Mathematics and Statistics Invention (IJMSI), 2(4), 40-46.

Kempa, R. (1986). Assessment in Science. Cambridge University Press, Cambridge, London.

Kızıltan, G. (2000). Başkent üniversitesi yiyecek içecek işletmeciliği programına kayıtlı öğrencilerin beslenme bilgi düzeyi ve beslenme durumuna beslenme eğitiminin etkisi. Beslenme ve Diyet Dergisi, 29(2), 34-41.

Küçükahmet, L. (2004). Öğretimde planlama değerlendirme. Ankara: Nobel Yayın Dağıtım.

Liu, X., \& Fulmer, G. (2008). Alignment between the science curriculum and assessment in selected NY state regents exams. Journal of Science Education and Technology, 17(4), 373-383.

Mertoğlu, H. (2002). İlköğretim 8. sınıf ögrrencilerinin beslenme kavramını ögrrenmelerinde aktif öğrenme yöntemlerinin etkisi. Yüksek lisans tezi, Eğitim Bilimleri Enstitüsü, Marmara Üniversitesi, İstanbul.

Narlı, S., ve Baser, N.E. (2008). "Küme, Bağıntı, Fonksiyon" konularında bir başarı testi geliştirme ve bu test ile üniversite matematik bölümü 1. sınıf öğrencilerinin bu konulardaki hazırbulunuşluklarını betimleme üzerine nicel bir araştırma. Dokuz Eylül Üniversitesi Buca Eğitim Fakültesi Dergisi, 24, 147-158.

Ogan Bekiroğlu, F. (2004). Ne kadar başarılı? Klasik ve alternatif ölçme- değerlendirme yöntemleri ve fizikte uygulamalar (1. baskl). Ankara: Nobel Yayın Dağıtım

Saderholm, J.C., \& Tretter, T.R. (2008). Identification of the most critical content knowledge base for middle school science teachers. Journal of Science Teacher Education, 19(3), 269-283.

Samaie, M., \& Khosravian, F. (2014). Achievement test development and validation: A measure of reading comprehension strategies for Iranian learners of English. International Journal of Linguistics, 6(2), 12-22. 
Saygın, M., Öngel, K., Çalışkan, S., Yağlı, M., Has, M., Gonca, T. ve Kurt, Y. (2011). Süleyman Demirel Üniversitesi öğrencilerinin beslenme alişkanliklari. SDÜ Tlp Fakültesi Dergisi, 18(2), 43-47.

Sireci, S.G., Hauger, J.B., Wells, C.S., Shea, C., \& Zenisky, A.L. (2009). Evaluation of the standard setting on the 2005 grade 12 national assessment of educational progress mathematics test. Applied Measurement in Education, 22(4), 339- 358.

Süel, E., Şahin, İ., Karakaya, M.A. ve Savucu, Y. (2006). Elit seviyedeki basketbolcuların beslenme bilgi ve alışkanlıkları. Fırat Üniversitesi Sağlık Bilimleri Tıp Dergisi, 20(4), 271-275.

Sümbül, E.İ. (2009). 4-6 yaş arasındaki öğrencilerin okul dönemindeki yetersiz ve dengesiz beslenme alışkanlıklarının saptanması, Doktora tezi, Sosyal Bilimler Enstitüsü, Selçuk Üniversitesi, Konya.

Şanlıer, N. ve Güler, A. (2005). İlköğretimin ikinci kademesinde eğitim gören öğrencilere verilen beslenme eğitiminin öğrencilerin beslenme bilgi düzeyi ve alışkanlıklarına etkisi. Beslenme ve Diyet Dergisi, 33(2), 31-38.

Şen, H. C. ve Eryılmaz, A. (2011). Bir başarı testi geliştirme çalışması: basit elektrik devreleri başarı testi geçerlik ve güvenirlik araştırması. Yüzüncü Yıl Üniversitesi, Eğitim Fakültesi Dergisi, 8(1), 1-39.

Tanrıverdi, D., Savaş, E., Gönüllüoğlu, N., Kurdal, E. ve Balık, G. (2011). Lise öğrencilerinin yeme tutumları, yeme davranışları ve benlik saygılarının incelenmesi. Gaziantep Medical Journal, 17(1), 33-39.

Tekin, H. (2000). Eğitimde ölçme ve değerlendirme. Ankara: Yarg1 Yayınları.

Timothy, Brown, A. (2006). Confirmatory Factor Analysis for Applied Research, New York, Guilford Press.

Turgut, M. F. (1992). Eğitimde ölçme ve değerlendirme. Ankara: Saydam Matbaacıllk.

Turgut, M.F. (1990). Türkiye'de fen ve matematik programlarını yenileme çalışmaları. Hacettepe Üniversitesi Ĕ̆itim Fakültesi Dergisi, 5(5), 1-14.

Turgut, M.F. ve Baykul, Y. (2010). Eğitimde ölçme ve değerlendirme. Ankara: Pegem Akademi Türkmen, N. (2005). Canlılar ve doğayla etkileşimleri’ ünitesine yönelik çoklu zeka kuramı tabanlı rehber materyal geliştirilmesi ve öğretim sürecindeki etkililiği. Yayımlanmamış Doktora Tezi, Fen Bilimleri Enstitüsü, Karadeniz Teknik Üniversitesi, Trabzon.

Uskun, E. ve Şabaplı, A. (2013). Lise Öğrencilerinin Beden Alg1ları ile Yeme Tutumları Arasındaki İlişki. TAF Preventive Medicine Bulletin, 12(5), 519-528. 
Ünal, Ç. ve Çelikkaya, T. (2009). Yapılandırmacı yaklaşımın sosyal bilgiler öğretiminde başarı, tutum ve kalıcılığa etkisi (5. sınıf örneği). Atatürk Üniversitesi Sosyal Bilimler Enstitüsü Dergisi, 13(2), 197-212.

Ünver, Y. (2004). Beş altı yaş okulöncesi dönemi çocukları đçin geliştirilecek, besin gruplarına yönelik beslenme ĕgitimi programlarının, çocukların beslenme bilgisi ve davranışlarına etkisi. Yüksek Lisans Tezi, Selçuk Üniversitesi Sosyal Bilimler Enstitüsü, Konya.

Yaman, S. (2003). Fen bilgisi ĕgitiminde probleme dayalı öğrenmenin öğrenme ürünlerine etkisi, Yayınlanmamış Doktora Tezi, Eğitim Bilimleri Enstitüsü, Gazi Üniversitesi, Ankara.

Yan, X., \& Erduran, S. (2009). Arguing online: case studies of pre-service science teachers' perceptions of online tools in supporting the learning of arguments. Journal of Turkish Science Education, 5(3), 2-31.

\section{Summary}

\section{Statement of Problem}

One of the biggest changes seen in parallel with the rapidly developing and changing world is seen in the eating habits. The habit of excessive and incorrect nutrition has become widespread nowadays. With this changes, many diseases, especially obesity, have emerged. These diseases should be prevented before they occur. Therefore, the awareness of balanced nutrition has gained importance. Schools have a great role in learning the nutrition that affects the physical and mental development of children. From an early age, students should learn how to be fed. The knowledge level of the students should be increased by education related to a balanced diet. The effect of the trainings on the level of knowledge of the students should be determined. When the literature is examined, it is seen that valid and reliable measurement instruments which can be used in academic studies on balanced nutrition are limited. The aim of this study is to develop a multiple choice achievement test that has validity and reliability in accordance with the unit named healthy and balanced nutrition. It is believed that balanced nutrition achievement test will meet the need for a valid and reliable academic achievement test by which teachers and researchers can use to determine students' readiness and learning levels.

\section{Method}


A multiple-choice achievement test was developed to measure the achievement of the 4th grade students in balanced nutrition subject in "Our Food Unit". The validity and reliability analyzes of achievement test were performed. In the process of developing the Balanced Nutrition Achievement Test, first of all, topics, concepts and learning gains within the unit of our nutrients were determined from the curriculum of the 4th grade Science course. Within the scope of the study, a pool of 35 multiple-choice questions was prepared to cover healthy and balanced nutrition gains. Achievement test was submitted to an expert opinion before final form, some of the questions were corrected according to the expert opinions and some of them were removed from the test and the number of questions was reduced to 30 . The achievement test was applied to 127 primary school 4th grade students, subjected to item analysis and validity reliability coefficients were calculated.

\section{Findings}

In order to ensure the construct validity of the test substances, the item was subjected to the analysis and the item discrimination indices and difficulty ratings calculated as a result of the item analysis were given in Table 1 . When Table 1 and Table 2 were examined, it was observed that fourteen items' discrimination indices were 0.40 and above, which show a very good discrimination value and nine items' discrimination indices of between 0.30 and 0.39 , which can be regarded to have good substance characteristic (Tekin, 2000). However , the items 9, 11, 13, 15, 18, 26 having low discriminant indices (0.20 and 0.29) and the items $7,17(0.19$ and smaller value), were decided to be removed from the test. Item 5 and item 26 with a difficulty level of less than 0.4 were excluded from the test due to the difficulty. Item 2 which had a difficulty level greater than 0.8 had been removed from the test because it was very easy. After applying item analysis, Academic Achievement Test were made up with 20 items , 12 of which have a discrimination index of 0.40 and above and 8 of them have $0.30-0.39$.

When Table 4 was analyzed, it was seen that the cronbach alpha coefficient of the balanced nutrition achievement test was .817. The Cronbach Alpha coefficient of $0.60 \leq \alpha<$ 0.90 reflects that the scores of the students are highly reliable (Can, 2014). The Spearman Brown Two Half Test correlation value was .70 and the Pearson Correlation value was .775.

\section{Discussion and Conclusion}


The aim of this study is to develop a multiple choice success test which provides validity and reliability in accordance with the healthy and balanced nutrition gains in our food unit. The achievement test which was prepared according to the test development stages was analyzed. In order to ensure the validity of the test, it is common in the literature to consult with the opinion of the faculty members (Akbulut ve Çepni, 2013; Şen ve Eryılmaz, 2011; Bingöl ve Halisdemir, 2017; Gürbüzöztürk, Aslan ve Et, 2017). According to expert opinions, the researchers have focused on the missing points of the test as to whether the multiple-choice achievement test measures the desired properties. The item analysis of the multiple-choice test was performed to provide the construct validity.

After the item analysis, the academic achievement test consisted of total 20 items; 12 items with a discriminant indices of 0.40 and above and 8 items with a discriminant indices of 0.30- 0.39. The highest score to be taken from the balanced nutrition achievement test is 20; the lowest score is 0 . The multiple choice academic achievement test has 4 options and the correct answers should be given "1" point, wrong and null answers should be given "0" points. As a result of the analyzes performed for the prepared achievement test, it was revealed that this was a valid and reliable test.

\section{Recommendations}

Balanced Nutrition achievement test is designed for 4th grade students. Considering the importance of balanced nutrition in the fight against obesity, it is recommended to develop balanced nutrition achievement test within different educational levels. 


\section{Ekler:}

\section{DENGELİ BESLENME BASSARI TESTI}

1) Alperen: Büyüme ve gelişmeyi sağlamak Asel: Yaşam enerjisi üretmek

Faruk: Vücut sağlığını korumak

Canlıların beslenme sebepleri arasında öğrencilerin söylediği özelliklerden hangileri vardır?
A)Yalnız Alperen
B)Alperen ve Asel
C)Alperen ve Faruk
D)Hepsi

2) Annesi Selim'e daima doğal besinler yemesini söylüyor. Buna göre Selim aşağıdakilerden hangisini yememelidir?
A)

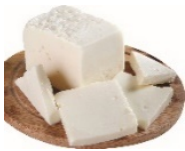

C)

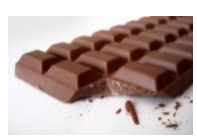

B)

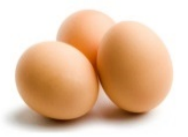

D)

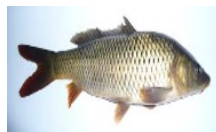

3) Aşağıdakilerden hangisi içerdiği besin yönüyle diğerlerinden farklıdır?
A)Makarna
B)Salata
C)Kek
D)Bisküvi

4)

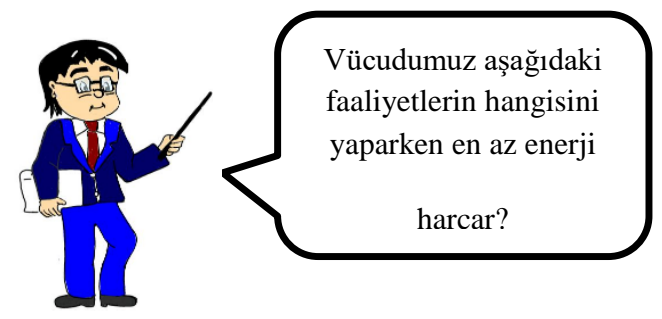

Ahmet öğretmenin sorusuna hangi öğrenci doğru cevap vermiştir?
A)Kitap okurken
B)Yürürken
C)Merdiven çıarken
D)Uyurken

5)

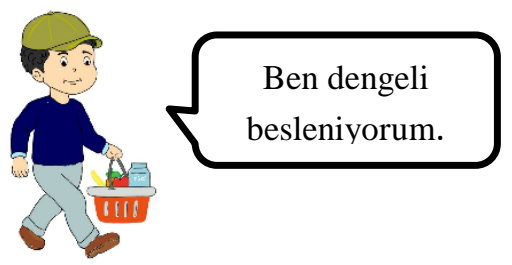

Ali böyle söylediğine göre aşağıdakilerden hangisini yapmaktadır?
A) Her çeşit besinden yeterince tüketmektedir
B) Hayvansal besinleri çokça tüketmektedir
C) Bitkisel besinleri çokça tüketmektedir
D) Bol vitaminli besinler tüketmektedir

6) Aşağıdakilerden hangisi bitkisel besindir?
A) Ayran
B) Bal
C)Ekmek
D)Yumurta

7) Aşağıdakilerden hangisi sağlıklı bir besinde olması gereken bir özelliktir?
A)Tarihinin geçmiş olması
B)Tadının tatlı olması
C)Taze olmas 1
D)Kirli olması

8)

Hayvanların etinden, sütünden ve yumurtasindan yararlanabiliriz.

Sevda öğretmenin söylediğine göre aşağıdaki hayvanların hangisinden bu şekilde vararlanamayı?
A)

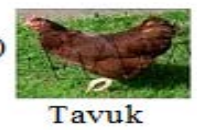

C)

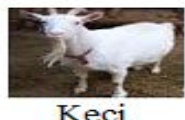

B)

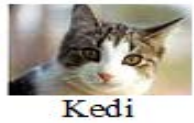

D)

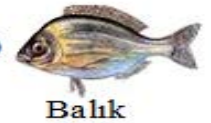


9)

\begin{tabular}{|l|l|l|}
\hline Yemekler & $\begin{array}{l}\text { Diğer } \\
\text { Besinler }\end{array}$ & İçecekler \\
\hline Yeşil fasulye & Elma & Kola \\
\hline Patates kzzartması & salata & Portakal suyu \\
\hline Domates çorbası & puding & \\
\hline Hamburger & & \\
\hline
\end{tabular}

Nur

Banu sağlıklı beslendiğini söylemektedir. Buna göre yukarda verilen yemek listesindeki hangi harfteki yiyecekleri secmemektedir?
A)Yeşil fasulye- domates çorbası-salata
B)Patates kızartmas1-hamburger-kola
C)Domates çorbası-salata- portakal suyu
D)Yeșil fasulye- domates çorbası-elma

10)

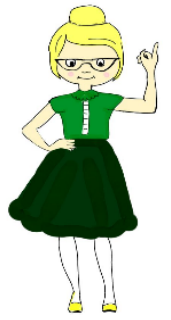

Kalsiyum kemik ve diş yapımız için oldukça gerekli bir mineraldir. Süt ve süt ürünlerinde bol miktarda bulunur.

Ece öğretmenin söylediğine göre büyümek için kalsiyumlu besinler yemek isteyen bir çocuk aşağıdaki besinlerden hangisini yememelidir?

A)

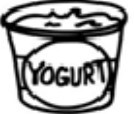

Yoğurt
B

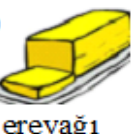

C)

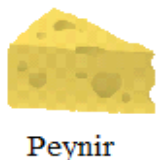

D)

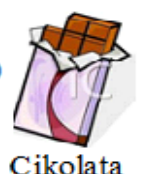

11)

Besinlerin taze olarak tüketilmesi en sağliklı yöntemdir.

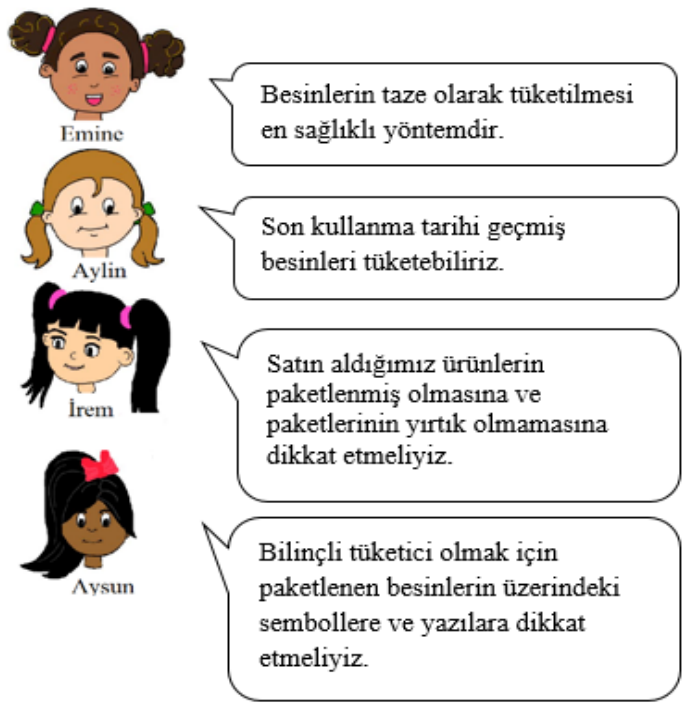

Besinlerin tazeliği ve bilinçli tüketim ile ilgili konuşan öğrencilerden hangisinin verdiği bilgi yanlıștır?
A)Emine
B)Aylin
C) İrem
D)Aysun

12)

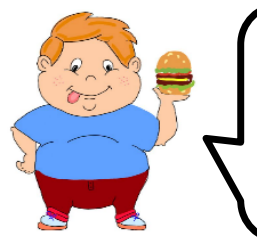

Can, dengesiz beslendiğini ve hiç egzersiz yapmadığını için obezite hastalı̆ğına yakalandığını öğreniyor.

Buna göre doktora giden Can'a doktor aşağıdakilerden hangisini yapmayı önerir?

A)Çok fazla hamburger yemelisin

B)Yağlı besinleri daha fazla tüketmelisin

C)Düzenli olarak spor yapmalısın

D)Sebze ve meyve tüketimini azaltmalısın

13)

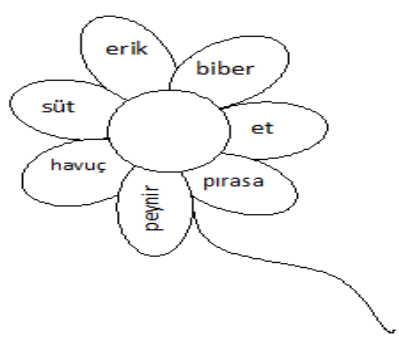

Yukarıdaki papatya yapraklarında bazı besinler yazılmıştır. Bitkisel kaynaklı besinlerin bulunduğu yapraklar boyandığında, aşağıdaki görünümlerden hangisi oluşur?
A)

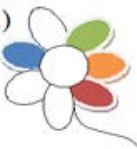

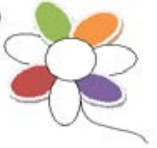

c)

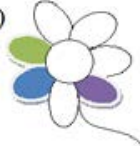

D)

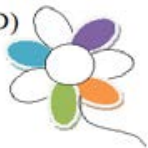

14)

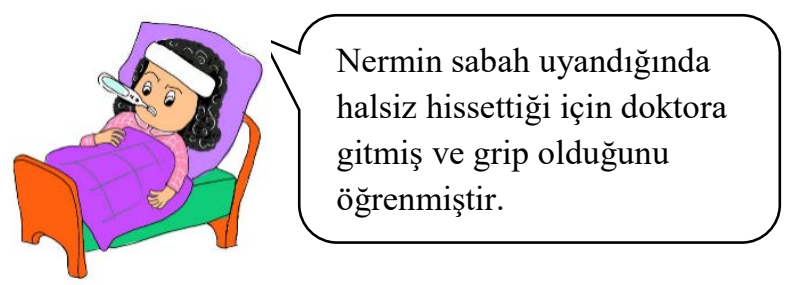

Nermin iyileşmek için hangi besinleri tüketmelidir?
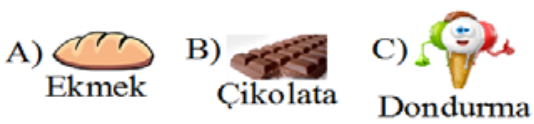

D) 
15)

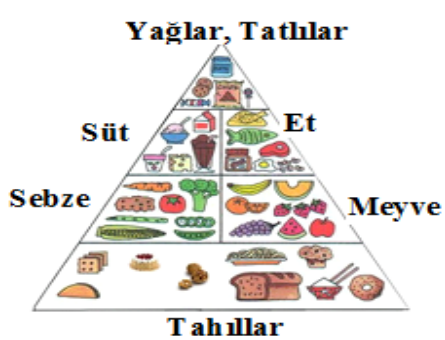

Piramitte en az tüketmemiz gereken besinlerin bulunduğu basamak hangisidir?

A)Yağlı besin, tahılların bulunduğu basamak

B)Süt ve etin bulunduğu basamak

C)Meyve ve sebzenin bulunduğu basamak

D)Tahılların bulunduğu basamak

16)

\begin{tabular}{|l|l|l|}
\hline Dengeli beslenmek için & DOĞRU & YANLIŞ \\
\hline $\begin{array}{l}\text { Yiyecekler taze ve temiz } \\
\text { olmalıdır. }\end{array}$ & & \\
\hline $\begin{array}{l}\text { Sebzeler doğranmış } \\
\text { olarak uzun zaman } \\
\text { bekletilmelidir. }\end{array}$ & & \\
\hline $\begin{array}{l}\text { Besinleri haşlamak } \\
\text { yerine kıartarak } \\
\text { yemeyi tercih etmeliyiz. }\end{array}$ & & \\
\hline $\begin{array}{l}\text { Pişmiş yemekler kapalı } \\
\text { kaplarda ve } \\
\text { buzdolabında } \\
\text { saklanmalıdır. }\end{array}$ & & \\
\hline
\end{tabular}

Yukarıda dengeli beslenme ile ilgili bir tablo verilmiştir.Buna göre tablonun doğru doldurulmuş hali aşağıdakilerden hangisi gibidir?
A)

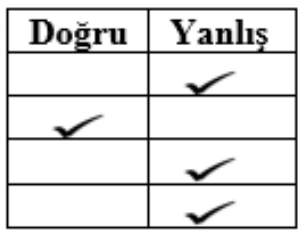

C)

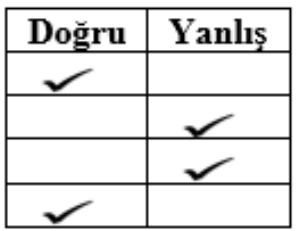

B)

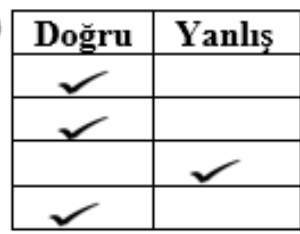

D)

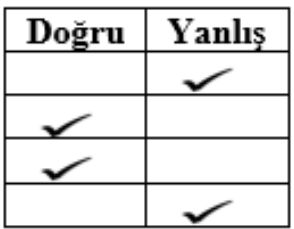

17) Besinler bitkisel ve hayvansal kaynaklı olmak üzere ikiye ayrılırlar. Buna göre aşağıdakilerden hangisi doğrudur?
A) Yumurta ve süt bitkisel besinlerdir

B) Sebze ve meyveler bitkisel besinlerdir

C) Yoğurt ve peynir bitkisel besinlerdir

D) Et ve tavuk bitkisel besinlerdir

18)

\begin{tabular}{|l|l|}
\hline Besinler & $\begin{array}{l}\text { Enerji Miktarları (100 } \\
\text { g) }\end{array}$ \\
\hline Tereyağı & 754 kalori \\
\hline Et & 260 kalori \\
\hline Makarna & 450 kalori \\
\hline
\end{tabular}

Yukarıda verilen bilgilere göre enerji miktarı fazla olan besinden düşük olan besine doğru sıralanış aşağıdakilerden hangisinde doğru verilmiştir?
A) Et - tereyağı - makarna
B) Tereyağı - et - makarna
C) Tereyağ 1 - makarna - et
D) Makarna - et - tereyağı

19)

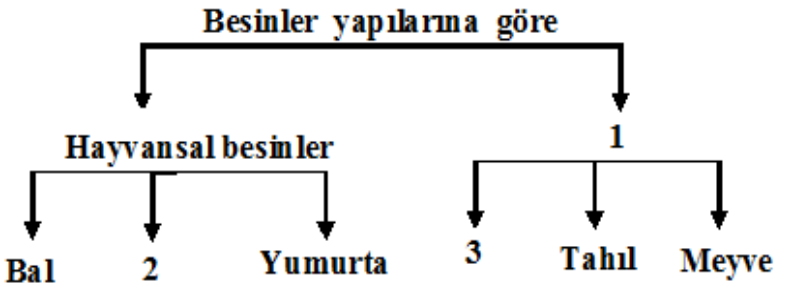

Yukarıdaki tabloya göre 1,2 ve 3 yerine ne yazılmalıdır?

\begin{tabular}{|c|c|c|c|}
\hline & 1 & 2 & 3 \\
\hline A & $\overline{\text { Sebze }}$ & Bitkisel & $\overline{\text { Süt }}$ \\
\hline 3) & Süt & Sebze & Bitkisel \\
\hline C) & Sebze & Bitkisel & Süt \\
\hline & Bitkisel & Süt & Sebze \\
\hline
\end{tabular}

20) Aşağıdakilerden hangisi yeterli ve dengeli beslenmek için yapılmaz?

A) Yaşa ve bedensel etkinliğe uygun miktarda besin tüketilmesi

B) Bir öğünde, tüm besin çeşitlerinden yeteri kadar alınması

C) Yağ ve şeker oranı fazla olan besinlerin tüketilmesi

D) Besinlerin sabah, öğle ve akșam ögünleri şeklinde tüketilmesi 